\title{
Extended biofilm susceptibility assay for Staphylococcus aureus bovine mastitis isolates: Evidence for association between genetic makeup and biofilm susceptibility
}

\author{
M. B. Melchior, ${ }^{\star 1,2}$ M. H. J. van Osch, ${ }^{\star}$ T. J. G. M. Lam,†‡ J. C. M. Vernooij,§ W. Gaastra,\# \\ and J. Fink-Gremmels* \\ *Department of Veterinary Pharmacology and Toxicology, Faculty of Veterinary Medicine, University of Utrecht, PO Box 80152,3508 TD Utrecht, \\ the Netherlands \\ †GD Animal Health Service, PO Box 9, 7400 AA Deventer, the Netherlands \\ fDutch Udder Health Centre, PO Box 2030, 7420 AA, Deventer, the Netherlands \\ $\S$ Department of Farm Animal Health, Faculty of Veterinary Medicine, University of Utrecht, Yalelaan 7, $3584 \mathrm{CL}$ Utrecht, the Netherlands \\ \#Department of Infectious Diseases and Immunology, Division of Molecular Infectiology, Faculty of Veterinary Medicine, University of Utrecht, \\ PO Box 80163, 3508 TD, Utrecht, the Netherlands
}

\begin{abstract}
Staphylococcus aureus is one of the most prevalent causes of bovine mastitis. The antimicrobial treatment of this disease is currently based on antimicrobial susceptibility tests according to Clinical and Laboratory Standards Institute standards. However, various authors have shown a discrepancy between the results of this standard susceptibility test and the actual cure rate of the applied antimicrobial treatment. Increasing evidence suggests that in vivo biofilm formation by Staph. aureus, which is not assessed in the antimicrobial susceptibility tests, is associated with this problem, resulting in disappointing cure rates, especially for infections of longer duration. Previous data obtained with a limited number of strains showed that the extended biofilm antimicrobial susceptibility (EBS) assay reveals differences between strains, which cannot be derived from a standard susceptibility test or from a 24-h biofilm susceptibility test. The objective of this study was to test a collection of Staph. aureus bovine mastitis strains in the EBS assay and to model the effect of antimicrobial exposure, duration of antimicrobial exposure, and genotype profile of the strains on antimicrobial susceptibility. With the results from a previous study with the same collection of strains, the effect of genotype represented by accessory gene regulator gene (agr-type), the presence of insertional sequence 257 (IS257), intercellular adhesion (ica), and the $\beta$-lactamase (blaZ) gene were entered as explanatory factors in a logistic regression model. The agr
\end{abstract}

\footnotetext{
Received February 7, 2011.

Accepted August 27, 2011.

${ }^{1}$ Corresponding author: marielle@mbmelchior.nl

${ }^{2}$ Current address: Central Veterinary Institute of Wageningen UR, Lelystad, marielle.melchior@wur.nl
}

locus of Staph. aureus controls the expression of most of the virulence factors, represses the transcription of several cell wall-associated proteins, and activates several exoproteins during the post-exponential phase. The IS257 gene has been related to biofilm formation in vitro and was found earlier in $50 \%$ of the agr-type 2 strains. The $i c a$ gene cluster encodes for the production of an extracellular polysaccharide adhesin, termed polysaccharide intercellular adhesin, which appears to have an important role in pathogenic Staph. aureus infections. The bla $Z$ gene encodes the presence of the penicillin resistance in the strain. The EBS assay together with the logistic regression model revealed that the duration of therapy is the most important factor of therapy outcome in this in vitro model. Furthermore, the effect of genotypic differences seems to be more important for therapy outcome than the antimicrobial used in this model.

Key words: mastitis, bacterial biofilm, antimicrobial susceptibility, Staphylococcus aureus

\section{INTRODUCTION}

Staphylococcus aureus is one of the major causes of subclinical, clinical, recurrent, and chronic mastitis in dairy cattle. These infections in dairy cows are often therapy resistant, which suggests that their potential to grow in a biofilm is related to the course of these persistent infections (Stewart, 2002; Melchior et al., 2006b). In several studies, it was shown that Staph. aureus bovine mastitis strains are able to form a bacterial biofilm (Vasudevan et al., 2003; Fox et al., 2005; Melchior et al., 2006a). Furthermore, a comparison of the results obtained with the standard Clinical and Laboratory Standards Institute (CLSI) susceptibility test with those obtained in a biofilm susceptibility assay for several antimicrobials commonly used for mastitis 
therapy revealed that these strains are less susceptible when growing in a bacterial biofilm (Olson et al., 2002; Melchior et al., 2006a, 2007).

From clinical trials and in vivo studies, it is known that several factors influence the outcome of Staph. aureus mastitis treatments: the duration of therapy (Sol et al., 2000; Oliver et al., 2004; Deluyker et al., 2005), the antimicrobial used (Deluyker et al., 1999; Taponen et al., 2003a; Bradley and Green, 2009), the penicillin susceptibility of the strain (Sol et al., 2000; Taponen et al., 2003b), and the duration of infection (Pyorala and Pyorala, 1998; van den Borne et al., 2010b). Furthermore, the response to therapy appears to be related to genotype (Haveri et al., 2007; van den Borne et al., 2010a) and the regional source of Staph. aureus strains, possibly representing different genetic backgrounds, also seems to influence the outcome of therapy (Bradley and Green, 2009). Up until now we have not been able to study all of these factors in an in vitro model, which would enable us to elucidate the molecular background of these factors, and would provide an in vitro platform for testing alternative therapeutic interventions.

In the year 2006, a representative collection of Staph. aureus bovine mastitis strains was gathered among Dutch dairy cows. Because of the low prevalence of penicillin resistance among these strains, 20 penicillinresistant strains from the Dutch veterinary antimicrobial resistance surveillance program were added to this collection (MARAN, 2005).

Previous data obtained with this collection of strains on the correlation between the biofilm-forming ability and the prevalence of several biofilm-related genes revealed some interesting features of the strains. First, a high correlation between the accessory gene regulator gene (agr-type) of the strains and the amount of biofilm formed by the strains was present; second, a high positive correlation between the agr-type 1 strains and the presence of $\beta$-lactamase resistance genes; and third, a high positive correlation between agr 2 strains and the presence of IS257 was observed (Melchior et al., 2009). The agr locus of Staph. aureus, which controls most of the virulence factors, encodes a 2-component signaling pathway whose activating ligand is an agr-encoded autoinducing peptide (AIP; Ji et al., 1997; Lyon et al., 2002; Chan et al., 2004). A polymorphism in the AA sequence of the AIP and of its corresponding receptor divides Staph. aureus strains into 4 major groups. Within each group, the strains produce a peptide that can activate the agr response in the other member strains of the same group, whereas the AIP belonging to different groups are usually mutually inhibitory ( $\mathrm{Ji}$ et al., 1997; Jarraud et al., 2002; Lyon et al., 2002). The role for insertional sequence 257 (IS257) in agr 2 strains, which is commonly associated with several resistance genes (i.e., the $\beta$-lactamase genes), was unclear, because it was not associated with any of the tested resistance genes (Melchior, 2007).

The intercellular adhesion (ica) gene cluster was found in $91 \%$ of the strains in this collection. The $i c a$ operon encodes the necessary enzymes for polysaccharide intercellular adhesion (PIA) or polymeric $\mathrm{N}$-acetylglucosamine (PNAG) production, which represents a well-defined biofilm-forming mechanism in staphylococci (O'Gara, 2007). In human infections, the presence of PNAG appears to have an important role in devicerelated infections, facilitating adherence and clumping of the strains (Ziebuhr et al., 1999). This could indicate that the role for the ica gene in Staph. aureus bovine mastitis isolates is outside the bovine udder, facilitating adherence and clumping to abiotic surfaces, such as the milking equipment.

The aim of the present study was to investigate the in vitro relation between several explanatory or predictive factors and the outcomes of the extended biofilm antimicrobial susceptibility (EBS) assay and measure the effects of these factors on the outcome of the assay in a logistic regression model. The factors entered in the final model were treatment, treatment duration, penicillin susceptibility, presence of IS257 and 2-way interactions between these factors.

\section{MATERIALS AND METHODS}

\section{Collection of Staph. aureus Isolates}

The Staph. aureus strains tested in this study originated from 2 collections: (A) field strains: samples were randomly collected in 2006 from 58 cows from 54 farms spread over the Netherlands. Milk samples were sent to the Dutch Animal Health Service Laboratories in Deventer [Gezondheidsdienst voor Dieren (GD), Deventer, the Netherlands]. Only 1 strain per cow was selected, and only 1 strain per farm was included in the study. These strains are designated as $\mathbf{F}$ strains.

(B) Penicillin-resistant Staph aureus strains: because of the low number of penicillin-resistant strains in collection F (approx. 10\%), which is in concordance with the current prevalence of penicillin resistance in the Netherlands (approx. 10\%; MARAN, 2003-2007), a sample of penicillin resistant strains was added to this collection, with the aim of having enough statistical power in the study. In total, 20 penicillin-resistant Staph. aureus strains from bovine mastitis cases from the Dutch antimicrobial surveillance program collected between 2003 and 2005 were obtained from the Central Veterinary Institute (CVI, Lelystad, the Netherlands) and were included. These strains are designated as $\mathbf{P}$ strains. 
All milk samples used in this study were incubated according to standard laboratory procedures (ISO 17025 certified laboratory) and the isolated Staph. aureus strains were stored at $-70^{\circ} \mathrm{C}$. Strains BMA/ UK/032/0106 and BMA/GE/032/0385, 2 penicillinresistant strains used in previous work (Melchior et al., 2006a), were used as control strains for the biofilm formation.

The growth medium used in the extended biofilm susceptibility assay (see below) was cation-adjusted Mueller-Hinton broth and this medium was also used in all recovery plates. All inocula to be used in antimicrobial susceptibility tests were freshly prepared from cultures grown overnight on sheep blood agar plates (bioTRADING Benelux BV, Mijdrecht, the Netherlands).

\section{Genetic Profile of Biofilm-Related Genes}

The agr type was detected according to the method of Gilot and van Leeuwen (Gilot et al., 2002). The presence of the $i c a A$ and $i c a D$ genes of the $i c a$ locus, and the IS257 gene was determined with primers described previously (Cramton et al., 1999; Sidhu et al., 2002). The presence of the $\beta$-lactamase (blaZ) gene in penicillin-resistant strains was confirmed with primers that were previously used by Olsen et al. (2006). For primers see Table 1.

\section{Extended Biofilm Susceptibility Assay for Bacteria Growing in Biofilms}

Measurements of the antimicrobial susceptibility of bacteria growing in biofilms were performed with the minimal biofilm eradication concentration (MBEC) assay (Ceri et al., 1999; Olson et al., 2002; Melchior et al., 2006a). In brief, bacterial biofilms were allowed to form on the surface of 96 pegs on the peg lid in the assay. The biofilms formed on all pegs were found to be statistically equivalent (Ceri et al., 1999) and were subsequently exposed in 96-well plates for a variable period of time to growth medium containing antimicrobials in different concentrations, to allow determination of the susceptibility of the bacteria grown in biofilm for these antimicrobial agents. The assay was performed as described previously (Ceri et al., 1999; Melchior et al., 2006a) with some modifications, which are adaptations for the extended biofilm susceptibility assay (Melchior et al., 2007).

Bacterial biofilms on the surface of the pegs were challenged with antimicrobials for 24 and $72 \mathrm{~h}$ with 2-fold antimicrobial dilution plates (Sensititer plates; MSC Diagnostics BC, Swalmen, the Netherlands). For the 72-h antimicrobial challenge, challenge plates were replaced every $24 \mathrm{~h}$ during 3 consecutive days. During this period, the 96 -well plates were incubated at $37^{\circ} \mathrm{C}$.

Minimal Biofilm Inhibitory Concentration. The minimal biofilm inhibitory concentration (MBIC) concentrations, the lowest concentration of antimicrobial that inhibits growth of the bacteria in the biofilm, were determined from all of the challenge plates after these plates had contained the peg lids for $24 \mathrm{~h}$. The presence of visible growth in the MBIC plates was determined by measuring the optical density at $655 \mathrm{~nm}$ in a 96-well plate reader (Bio-Rad plate reader; Bio-Rad Laboratories Inc., Hercules, CA).

Minimal Biofilm Eradication Concentration. The MBEC d 1 and 3 concentrations, the lowest concentration of antimicrobial able to eradicate the bacteria in the biofilm, were determined after $24 \mathrm{~h}$ (d 1) and $72 \mathrm{~h}(\mathrm{~d} \mathrm{3})$ of antimicrobial challenge respectively, by loading the peg lid of the MBEC assay in a 96-well recovery plate containing cation-adjusted MuellerHinton broth $(200 \mu \mathrm{L})$ in each well. After sonication

Table 1. Primers used for genotyping for the biofilm-related genes

\begin{tabular}{|c|c|c|}
\hline Primer $\left(5^{\prime}-3^{\prime}\right)^{1}$ & Sequence & Reference \\
\hline Pan & ATG CAC ATG GTG CAC ATG C & Gilot et al. (2002) \\
\hline agr 1 & GTC ACA AGT ACT ATA AGC TGC GAT & \\
\hline agr 2 & TAT TAC TAA TTG AAA AGT GGC CAT AGC & \\
\hline $\operatorname{agr} 3$ & GTA ATG TAA TAG CTT GTA TAA TAA TAC CCA G & \\
\hline agr 4 & CGA TAA TGC CGT AAT ACC CG & \\
\hline ica $\mathrm{AF}$ & CCT AAC TAA CGA AAG GTA G & Cramton et al. (1999) \\
\hline$i c a \mathrm{AR}$ & AAG ATA TAG CGA TAA GTG C & \\
\hline$i c a \mathrm{DF}$ & AAA CGT AAG AGA GGT GG & \\
\hline ica DR & GGC AAT ATG ATC AAG ATA C & \\
\hline 487 & TAA GAG ATT TGC CTA TGC TT & Olsen et al. (2006) \\
\hline 373 & TTA AAG TCT TAC CGA AAG CAG & \\
\hline$I S 257 \mathrm{~F}$ & TTG GGT TCA AGA ATA TGC CC & Sidhu et al. (2002) \\
\hline$I S 257 \mathrm{R}$ & CTT CGT TGA AGG TGC CTG AT & \\
\hline
\end{tabular}


of the peg lid and recovery plate for 5 min (Branson sonicator; Branson Ultrasonics Corp., Danbury, CT), the plate was incubated overnight at $37^{\circ} \mathrm{C}$. The presence of visible bacterial growth in the recovery plates was determined by measuring the optical density at $655 \mathrm{~nm}$ in a 96-well plate reader (Bio-Rad plate reader, Bio-Rad Laboratories Inc.).

The assays were performed in duplicate and in 2 independent experiments. The resulting MBIC and MBEC values are the means of the lowest antimicrobial dilution without visible growth from these 4 assays, rounded off at the lowest dilution concentration used in the assay. Quality controls were performed according to the MBEC protocols (http://www.innovotech.ca/ products_use.php) and the number of colony-forming units per peg was calculated for all assays.

The concentrations of the antimicrobials used in the assays ranged between 0.5 and $512 \mu \mathrm{g} / \mathrm{mL}$ for amoxicillin/clavulanic acid (ratio 2:1) and cloxacillin and between 0.12 and $128 \mu \mathrm{g} / \mathrm{mL}$ for penicillin and penicillin/ neomycin (ratio 2:1).

\section{Statistical Analysis of the Data}

The data from the EBS assay and the genotyping results were collected in an Excel (Microsoft Corp., Redmond, WA) file. The data were exported to SPSS statistics 17.0 (SPSS Inc., Chicago, IL), and explored both visually and with descriptive statistics. Distributions of variables were assessed, correlations between variables within the model were investigated, and transformations were carried out based on the CLSI susceptibility breakpoints (penicillin $\leq 0.12 \mu \mathrm{g} / \mathrm{mL}$, neomycin $\leq 16 \mu \mathrm{g} / \mathrm{mL}$, amoxicillin with clavulanic acid $\leq 4 \mu \mathrm{g} / \mathrm{mL}$, and cloxacillin $\leq 2 \mu \mathrm{g} / \mathrm{mL}$ ) and the MBEC outcomes in the EBS assay. The MBEC outcomes equal to or lower than the CLSI susceptibility breakpoints were transformed to a value of 0 , indicating a susceptible strain, and MBEC outcomes higher than CLSI susceptibility breakpoints were transformed to a value of 1 , indicating a resistant strain. For the combination of penicillin with neomycin, the antimicrobial challenge was considered to be a susceptible strain if at least 1 of the antimicrobial concentrations was equal to or lower than breakpoint values. All CLSI breakpoints used for interpretation of the data are based on human data, as veterinary breakpoints are not available.

An SPSS data set was compiled with all strains, the MBEC assay outcomes, and the explanatory variables of these strains. For the analysis of the data set, the lme4 library (Bates et al., 2008) of $\mathrm{R}$ version 2.7.2 (R Development Core Team, 2008) was used. This logistic regression model was used to model the binary outcomes of the MBEC assay. To correct for correlation between the multiple observations in strains, a random effect was added. The explanatory variables tested in the model were treatment $[1=$ penicillin (pen), $2=$ neomycin penicillin (neopen), $3=$ amoxicillin clavulanic acid (amoxyclav), $4=$ cloxacillin (clox)], treatment duration ( 1 or $3 \mathrm{~d})$, penicillin susceptibility $(0=$ resistant, 1 = susceptible), IS257 ( $0=$ without IS257, 1 $=$ with IS257), and $i c a(0=$ without $i c a$ locus, $1=$ with ica locus). The observations of treatment 2 were excluded from the analysis due to $100 \%$ susceptibility of the samples. Due to convergence, the model could not be run with both penicillin susceptibility and agr-type as explanatory variables; thus, for practical reasons, we choose to run the model with penicillin susceptibility. Also 2-way interactions between the first 4 variables were added to the model. A forward selection procedure was used due to convergence problems in the full model especially caused by the interaction of treatment duration and penicillin susceptibility. First, all main effects were added and then, stepwise, one 2-way interaction term was added. For selection of the best model, Akaike's Information Criterion was used.

\section{RESULTS}

The results of the genotyping are compiled in Table 2. The results from the field strains show that most strains were agr $2(84.5 \%)$, and that all of the agr 2 strains were penicillin susceptible. The other $\mathrm{F}$ strains were predominantly agr 1 and $50.0 \%$ of field strains from agr 1 were penicillin resistant. The IS257 was most common among agr 2 strains (46.9\%); however, $23.1 \%$ of $\operatorname{agr} 1$ strains also contain the IS257 gene. The ica gene was present in all agr 2 strains, and in $73.1 \%$ of agr 1 strains.

The agr 3 and agr 4 groups are rarely found in our set of bovine mastitis isolates. Detection of the blaZ gene was confirmed with PCR in all but 1 penicillin-resistant strain, which was agr 2. This strain was negative in a mecA PCR (data not shown; see Table 2).

The quality controls of the biofilm assays showed that the biofilms of all strains in all experiments grew to a mean density of $1.1 \times 10^{7}$ cfu per peg; however, important differences could be observed between strains (see Figure 1). The agr II, IS25\%-positive strains produced 1 $\log$ less $\mathrm{cfu} /$ peg compared with the mean of all strains (Figure 1); these strains were also grown for $48 \mathrm{~h}$ in the MBEC extended assay, which resulted in a higher density of bacterial biofilm (data not shown).

The MBIC concentrations for all strains were in the same range of 1 dilution step for all measurements, on all days, and in repeated assays; therefore, the concentrations are presented as a single value. The results are presented in Tables 3 and 4, including the susceptibility 


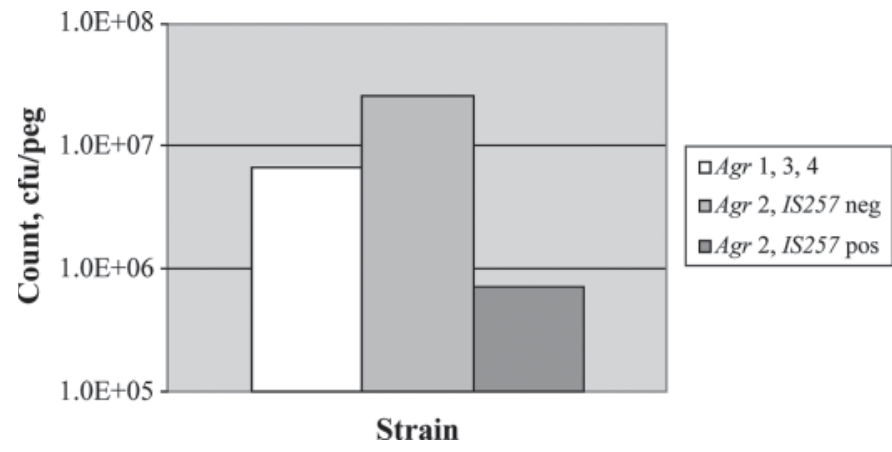

Figure 1. Number of colony forming units per peg [on the peg lid of the minimal biofilm eradication concentration (MBEC) assay] from different strain types after $24 \mathrm{~h}$ of growth. Agr = accessory gene regulator gene; IS257 = insertional sequence 257 ; neg = negative; pos $=$ positive.

breakpoints, according to CLSI guidelines, indicated as horizontal bars. Results reveal that a high concentration of penicillin was needed for inhibition of growth for agr 1, 3, and 4 strains, whereas $96 \%$ of agr 2 strains were inhibited at a penicillin concentration $\leq 0.12$ $\mu \mathrm{g} / \mathrm{mL}$. The combination of penicillin with neomycin (ratio 2:1) resulted in inhibition of growth for almost all strains with a penicillin concentration $\leq 0.12 \mu \mathrm{g} /$ $\mathrm{mL}$. Amoxicillin with clavulanic acid and cloxacillin inhibited growth at concentrations of $\leq 4$ and $\leq 2 \mu \mathrm{g} /$ $\mathrm{mL}$, respectively, for 100 and $96 \%$ of strains. The single strain with an MBIC concentration of $4 \mu \mathrm{g} / \mathrm{mL}$ was not found to contain the mecA gene (data not shown).
The MBEC values for penicillin for the agr 1, 3, and 4 strains were very high at $\mathrm{d} 1$, and were slightly lower on d 3; however, still more than $93 \%$ were higher or equal to $2 \mu \mathrm{g} / \mathrm{mL}$ at d 3 (see Table 5). These penicillin concentrations are higher than what can be expected in vivo with standard mastitis therapy; therefore, these strains, as can be expected because $82.8 \%$ carry $\beta$-lactamase genes (see Table 2), behave like true penicillin-resistant strains in the biofilm. For the agr 2 strains, eradication from the biofilm was reached at d 3 for the majority of strains (see Table 5). The data for the combination of penicillin and neomycin clearly show the additional effect of neomycin for agr 1, 3, and 4 strains. However, the results also revealed that, after d 3, these strains had a bimodal distribution, with $38 \%$ of strains eradicated at a concentration of $0.06 \mu \mathrm{g} / \mathrm{mL}$ and $24 \%$ of strains eradicated at $4 \mu \mathrm{g} / \mathrm{mL}$. For the $a g r$ 2 strains, the synergy between these antimicrobials was not clear, as for most strains eradication was reached on both days at higher penicillin concentrations compared with penicillin alone (see Table 5).

For the combination of the antimicrobials amoxicillin and clavulanic acid and for cloxacillin, similar results were obtained with most strain types (Table 6). The most obvious difference between strain types was the increased susceptibility for agr 2 strains with IS257, as these strains were clearly the most susceptible strains for the antimicrobials tested in this study. The baseline characteristics of the strains in the EBS model are summarized in Table 7.

Table 2. Characteristics of the bacterial strains used in this study, based on genotyping of the accessory gene regulator gene $(a g r)$ and $\beta$-lactamase gene (blaZ), penicillin susceptibility based on Clinical and Laboratory Standards Institute (CLSI) breakpoint values, and the presence of the insertional sequence 257 (IS257) and intercellular adhesion $(i c a)$ genes

\begin{tabular}{|c|c|c|c|c|c|}
\hline \multirow[b]{2}{*}{ Isolate } & \multirow[b]{2}{*}{ No. $(\%)^{1}$} & \multicolumn{4}{|c|}{ Percentage of isolates with: } \\
\hline & & blaZ & $\begin{array}{l}\text { Penicillin } \\
\text { resistance }\end{array}$ & IS257 & $i c a$ \\
\hline F strain & $58(74.4)$ & 6.9 & 8.6 & 43.1 & 91.4 \\
\hline agr 1 & $8(10.3)$ & 50.0 & 50.0 & 3.4 & 37.5 \\
\hline agr 2 & $49(62.8)$ & - & $2.0^{2}$ & 46.9 & 100.0 \\
\hline agr 3 & $1(1.3)$ & - & - & - & 100.0 \\
\hline agr 4 & - & - & - & - & - \\
\hline $\mathrm{P}$ strain & $20(25.6)$ & 100.0 & 100.0 & 20.0 & 90.0 \\
\hline agr 1 & $18(23.1)$ & 100.0 & 100.0 & 22.0 & 88.9 \\
\hline agr 2 & - & - & - & - & - \\
\hline agr 3 & $1(1.3)$ & 100.0 & 100.0 & - & 100.0 \\
\hline agr 4 & $1(1.3)$ & 100.0 & 100.0 & - & 100.0 \\
\hline \multicolumn{6}{|c|}{ All strains } \\
\hline agr 1 & $26(33.3)$ & 84.6 & 84.6 & 23.1 & 73.1 \\
\hline agr 2 & $49(62.8)$ & - & 2.0 & 46.9 & 100.0 \\
\hline agr 3 & $2(2.6)$ & 50.0 & 50.0 & - & 100.0 \\
\hline agr 4 & $1(1.3)$ & 100.0 & 100.0 & - & - \\
\hline Total & 78 (100) & 30.8 & 32.1 & 42.3 & 91.0 \\
\hline
\end{tabular}

${ }^{1}$ The percentage in parentheses is related to the total amount of strains in the study $(\mathrm{n}=78)$.

${ }^{2}$ One agr 2 strain was penicillin resistant according to the CLSI breakpoints; however, this strain was negative for the blaZ gene in the $\beta$-lactamase PCR tests. 
Table 3. Minimal biofilm inhibitory concentration (MBIC) values for penicillin and penicillin with neomycin (Pen/neo) for all strain types in the extended minimal biofilm eradication concentration (MBEC) assay

\begin{tabular}{|c|c|c|c|c|c|c|c|c|c|c|c|c|c|c|}
\hline Item $^{2}$ & $\mathrm{n}$ & \multicolumn{13}{|c|}{ Percentage of strains at each indicated MBIC, $\mu \mathrm{g} / \mathrm{mL}$} \\
\hline agr 2, IS257 neg & 26 & 92.3 & 3.8 & & & & & & & & & 3.8 & & 21.0 \\
\hline agr 2, IS 257 pos & 23 & 100.0 & & & & & & & & & & & & \\
\hline \multicolumn{15}{|l|}{ Pen/neo $(2: 1)$} \\
\hline agr 2, IS257 pos & 23 & 100.0 & & & & & & & & & & & & \\
\hline
\end{tabular}

${ }^{1}$ The concentration indicated for the penicillin with neomycin is based on the penicillin concentration. The susceptibility breakpoints according to Clinical and Laboratory Standards Institute (CLSI) guidelines: $\leq 0.12 \mu \mathrm{g} / \mathrm{mL}$ for penicillin and $<16 \mu \mathrm{g} / \mathrm{mL}$ for neomycin [ratio $2: 1$; the breakpoint of neomycin was adapted for the concentration ratio of 2:1 in the extended biofilm antimicrobial susceptibility (EBS) assay]. All interpretive criteria are based on human data.

${ }^{2} a g r=$ accessory gene regulator gene; $I S 257=$ insertional sequence 257 ; neg $=$ negative; pos $=$ positive.

Table 4. Minimal biofilm inhibitory concentration (MBIC) for amoxicillin with clavulanic acid (Amoxy/clav; ratio 2:1) and cloxacillin in the extended minimal biofilm eradication concentration (MBEC) assays ${ }^{1}$

\begin{tabular}{|c|c|c|c|c|c|c|c|c|c|c|c|c|c|c|}
\hline Item $^{2}$ & $\mathrm{n}$ & \multicolumn{13}{|c|}{ Percentage of strains at each indicated MBIC, $\mu \mathrm{g} / \mathrm{mL}$} \\
\hline \multicolumn{15}{|l|}{ Amoxy/clav (2:1) } \\
\hline $\operatorname{agr} 1,3,4$ & 29 & 17.2 & 3.4 & 24.4 & 41.4 & 13.8 & & & & & & & & \\
\hline agr 2, IS257 neg & 26 & 38.5 & 26.9 & 26.9 & 7.7 & & & & & & & & & \\
\hline agr 2, IS257 pos & 23 & 95.7 & 4.3 & & & & & & & & & & & \\
\hline \multicolumn{15}{|l|}{ Cloxacillin } \\
\hline agr 2, IS257 pos & 23 & 82.6 & 17.4 & & & & & & & & & & & \\
\hline
\end{tabular}

${ }^{1}$ The susceptibility breakpoints according to Clinical and Laboratory Standards Institute (CLSI) guidelines: $\leq 4 \mu \mathrm{g} / \mathrm{mL}$ for amoxicillin-clavulanic acid and $\leq 2 \mu \mathrm{g} / \mathrm{mL}$ for cloxacillin.

${ }^{2} a g r=$ accessory gene regulator gene; $I S 257=$ insertional sequence 257 ; neg = negative; pos = positive.

Table 5. Minimal biofilm eradication concentration (MBEC) values for penicillin and penicillin with neomycin (Pen/neo) for all strain types in the extended biofilm antimicrobial susceptibility (EBS) assays ${ }^{1}$

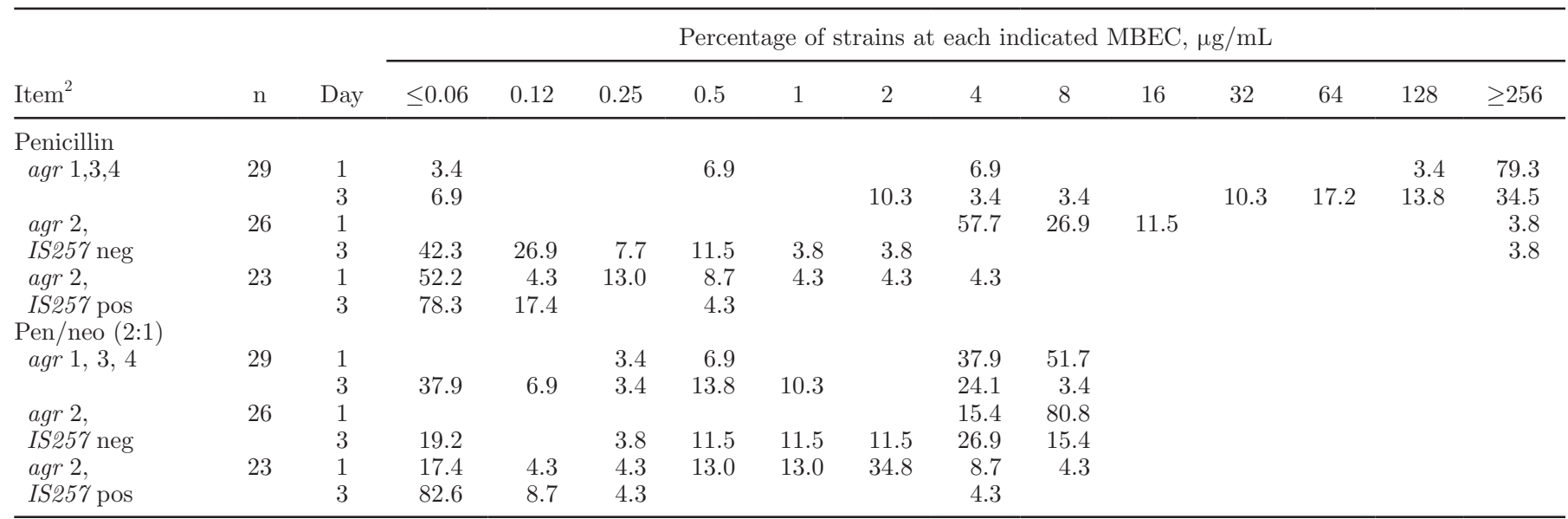

${ }^{1}$ The concentration indicated for penicillin with neomycin is based on the penicillin concentration. The susceptibility breakpoints according to Clinical and Laboratory Standards Institute (CLSI) guidelines: $\leq 0.12 \mu \mathrm{g} / \mathrm{mL}$ for penicillin and $\leq 16 \mu \mathrm{g} / \mathrm{mL}$ for neomycin (ratio $2: 1$; the breakpoint of neomycin was adapted for the concentration ratio of $2: 1$ in the EBS assay).

${ }^{2} a g r=$ accessory gene regulator gene; $I S 257=$ insertional sequence 257 ; neg $=$ negative; pos $=$ positive. 
Table 6. Minimal biofilm eradication concentration (MBEC) values for amoxicillin with clavulanic acid (Amoxy/clav; ratio 2:1) and cloxacillin for all strain types in the extended biofilm antimicrobial susceptibility (EBS) assays ${ }^{1}$

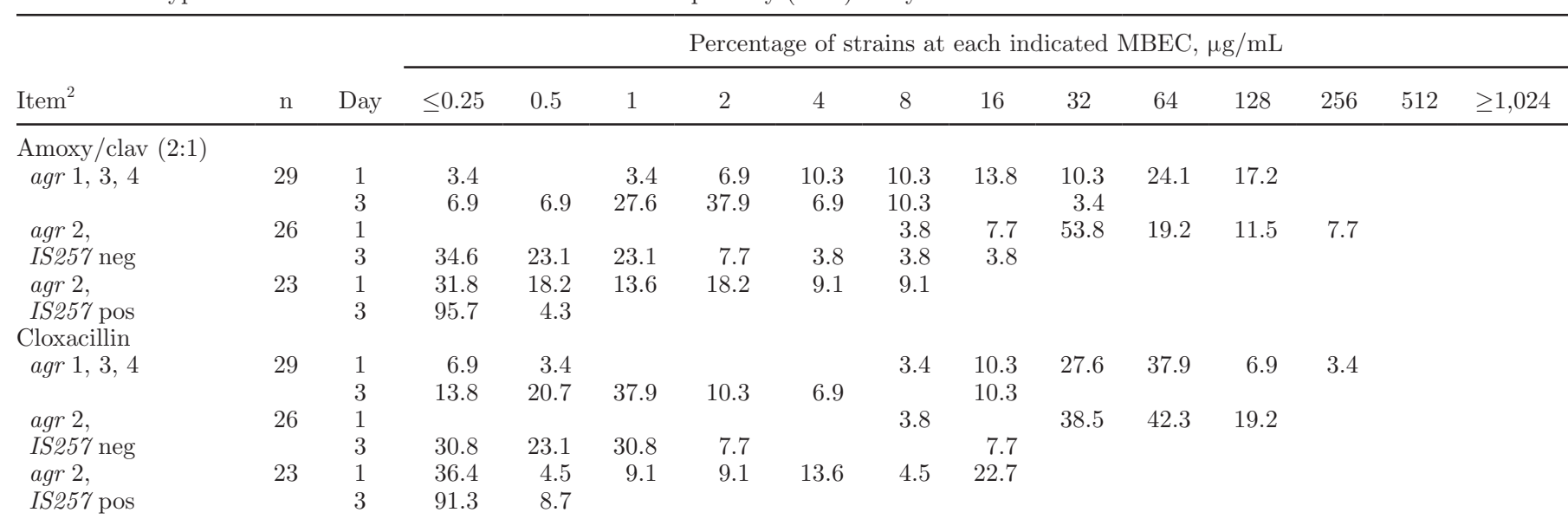

${ }^{1}$ The susceptibility breakpoints according to Clinical and Laboratory Standards Institute (CLSI) guidelines: $\leq 4 \mu \mathrm{g} / \mathrm{mL}$ for amoxicillin with clavulanic acid and $\leq 2 \mu \mathrm{g} / \mathrm{mL}$ for cloxacillin.

${ }^{2} a g r=$ accessory gene regulator gene; IS257 = insertional sequence $257 ;$ neg $=$ negative; pos $=$ positive.

The results of the logistic regression model are presented in Table 8 as the odds of MBEC $=0$ (= susceptible strain) The reference group of the model, which is compared with other factors, is the antimicrobial treatment in the EBS assay of a penicillin-resistant strain (0), without IS257 (0), with treatment 1 (penicillin), for $1 \mathrm{~d}$ (1). Treatment 2 (penicillin/neomycin) had to be excluded from the model, because all outcomes were in the susceptible group. Due to convergence problems, it was not possible to include the agr type in the model together with penicillin susceptibility status (see Table
2 ). Because of the more general presence of information on the penicillin susceptibility of Staph. aureus bovine mastitis strains in practice, we chose to include penicillin susceptibility in the model.

The model revealed no significant differences between treatments 1,3 , and 4 , and this is remarkable because $32 \%$ of the strains were penicillin resistant, and one might expect significantly better results with treatment 3 (amoxicillin with clavulanic acid) and treatment 4 (cloxacillin). The interaction factors between treatment (3 and 4 ) and penicillin susceptibility were highly sig-

Table 7. Baseline characteristics of the results entered in the logistic regression model

\begin{tabular}{|c|c|c|c|c|}
\hline \multirow[b]{3}{*}{ Item $^{1}$} & \multicolumn{4}{|c|}{$\%$ of isolates with MBEC above CLSI breakpoints ${ }^{2}$} \\
\hline & \multicolumn{2}{|c|}{ MBEC d 1 (24 h) } & \multicolumn{2}{|c|}{ MBEC d $3(72 \mathrm{~h})$} \\
\hline & Mean & $95 \% \mathrm{CI}$ & Mean & $95 \% \mathrm{CI}$ \\
\hline All treatments & 0.57 & $0.51-0.62$ & 0.16 & $0.12-0.20$ \\
\hline Penicillin & 0.82 & $0.73-0.91$ & 0.46 & $0.35-0.57$ \\
\hline $\begin{array}{l}\text { Neomycin-penicillin }(2: 1) \\
\text { Amoxicillin-clavulanic acid }\end{array}$ & $\overline{0}^{\circ} 65$ & $0.55-0.76$ & $\overline{0}_{08}^{0}$ & \\
\hline & 0.65 & $0.00-0.10$ & 0.08 & $0.02-0.14$ \\
\hline $\begin{array}{l}\text { Cloxacillin } \\
\text { Dependent variable }\end{array}$ & 0.79 & $0.70-0.89$ & 0.09 & $0.02-0.15$ \\
\hline \multicolumn{5}{|l|}{ Dependent variable } \\
\hline ica positive & 0.56 & $0.51-0.62$ & 0.14 & $0.10-0.18$ \\
\hline IS257 positive & 0.34 & $0.25-0.42$ & 0.07 & $0.02-0.12$ \\
\hline$\beta$-lactamase positive ${ }^{4}$ & 0.69 & $0.60-0.78$ & 0.30 & $0.21-0.39$ \\
\hline agr 1 & 0.64 & $0.55-0.74$ & 0.30 & $0.21-0.39$ \\
\hline agr 2 & 0.52 & $0.44-0.59$ & 0.07 & $0.03-0.10$ \\
\hline agr 3 & 0.75 & $0.36-1.14$ & 0.50 & $0.05-0.95$ \\
\hline agr 4 & 0.75 & $-0.05-1.55$ & 0.25 & $-0.55-1.05$ \\
\hline
\end{tabular}

${ }^{1} i c a=$ intercellular adhesion gene; $I S 257=$ insertional sequence 257 ; agr = accessory gene regulator gene.

${ }^{2} \mathrm{MBEC}=$ minimal biofilm eradication concentration; CLSI $=$ Clinical and Laboratory Standards Institute.

${ }^{3}$ The neomycin penicillin treatment was excluded from the model because all outcomes collided in the same outcome group, which was an outcome below CLSI breakpoints.

${ }^{4} \beta$-lactamase-positive strains are all penicillin resistant according to CLSI breakpoints. 
Table 8. Odds ratios (OR) and $95 \%$ confidence intervals in the final model

\begin{tabular}{|c|c|c|c|c|c|}
\hline \multirow[b]{2}{*}{ Factor $^{1}$} & \multirow[b]{2}{*}{$\beta$} & \multirow[b]{2}{*}{ OR } & \multirow[b]{2}{*}{ Sig. ${ }^{2}$} & \multicolumn{2}{|c|}{ CI limit } \\
\hline & & & & Lower & Upper \\
\hline Intercept & 6.3028 & & $* * *$ & & \\
\hline Treatment 3 (amoxy/clav) & -1.5146 & 4.55 & & 0.59 & 35.09 \\
\hline Treatment 4 (cloxacillin) & -0.6235 & 1.87 & & 0.22 & 15.50 \\
\hline IS257 1 & 0.2962 & 0.74 & & 0.04 & 13.66 \\
\hline Treatment 1: treatment duration $3 \mathrm{~d}$ & -4.5027 & 90.09 & $* * *$ & 16.95 & 476.19 \\
\hline Treatment 3: treatment duration $3 \mathrm{~d}$ & -7.4271 & $1,666.67$ & $* * *$ & 238.10 & $11,994.41$ \\
\hline Treatment 4: treatment duration $3 \mathrm{~d}$ & -8.3609 & $5,000.00$ & $* * *$ & 555.56 & $32,688.94$ \\
\hline IS257 0: pen susceptibility 1 & -1.6216 & 5.06 & & 0.92 & 27.86 \\
\hline IS257 1: pen susceptibility 1 & -6.8029 & 909.09 & $* * *$ & 54.05 & $15,030.73$ \\
\hline Treatment 3 (amoxy/clav): IS257 1 & -2.6227 & 13.07 & $*$ & 1.24 & 153.85 \\
\hline Treatment 4 (cloxacillin): IS257 1 & 0.2558 & 0.77 & & 0.08 & 7.14 \\
\hline
\end{tabular}

${ }^{1}$ Amoxy $/$ clav $=$ amoxicillin with clavulanic acid; IS257 = insertional sequence 257 .

${ }^{2}$ Significance (Sig.) codes: ${ }^{* * *} P<0.001 ; * P<0.1$.

nificant; however, due to very large standard errors we were able to significantly improve the model by deleting this factor.

The most important factors in the outcomes of the model were the interactive effects between treatments 1,3 , and 4 and the duration of the treatment $(3 \mathrm{~d})$, and they were highly significant. Typically, where the odds ratio for treatment 4 (cloxacillin) was somewhat lower than for treatment 3 (amoxicillin with clavulanic acid), the odds ratio for the interaction factor between treatment 4 and treatment duration $(3 \mathrm{~d})$ was clearly higher than for treatment 3 and treatment duration.

Two genotypic factors in the strains were of influence on the outcomes; the presence of IS257 alone, and the presence of IS257 and penicillin susceptibility. With the addition of the interaction factor between IS257 and penicillin susceptibility, the influence of IS257 alone was not significant any more. The presence of ica had little effect on the outcomes and was lost in the final model.

\section{DISCUSSION}

To investigate if the EBS assay is a suitable model to study the discrepancy between the high in vitro susceptibility, and the disappointing bacteriological cure after therapy in Staph. aureus bovine mastitis infections, 78 recently isolated strains were tested in the EBS assay. Previous results have shown a very good correlation between a standard CLSI antimicrobial susceptibility assay and the MBIC outcomes of the biofilm assay (Ceri et al., 1999; Melchior et al., 2006a). The MBIC results showed that almost $10 \%$ of field strains were penicillin resistant, which was in agreement with the presence of a blaZ gene in these strains, with exception of one strain where presence of this gene could not be confirmed. Based on the good correlation between the
MBIC outcomes and standard susceptibility tests in previous studies, we have used this to identify susceptible and resistant strains for the antimicrobials used in this study.

The MBEC outcomes of the biofilm assay show that the bacteria in the biofilm are able to withstand considerably higher antimicrobial concentrations without apparent loss of fitness, even after several days of antimicrobial challenge (Melchior et al., 2007). The results of numerous in vivo studies have shown the resilience of Staph. aureus bacteria in the bovine udder, resulting in therapeutic failures and chronic infections despite antimicrobial treatments and good antimicrobial susceptibility. Epidemiological studies have shown that several factors not related to the antimicrobial susceptibility pattern for the antimicrobials used in the study are related to the efficacy of antimicrobial therapy. These are, among others, the duration of therapy (Sol et al., 2000; Oliver et al., 2004; Deluyker et al., 2005), the antimicrobial used (Deluyker et al., 1999; Taponen et al., 2003a), the penicillin susceptibility of the strain (Sol et al., 2000; Taponen et al., 2003b), the genetic background of the strains, and the duration of infection (Pyörälä and Pyörälä, 1998; Haveri et al., 2005; van den Borne et al., 2010a,b). Typically, the penicillin susceptibility would seem irrelevant, as the studies applied antimicrobials for which the strains were actually susceptible.

The EBS model enables us to model the in vitro effects of duration of therapy, antimicrobials used, penicillin susceptibility of the strains, the genetic background of the strains, and the duration of growth on the MBEC outcomes of the assay. The effect of treatment variables (treatment duration and choice of antimicrobial drug) and strain variables (blaZ gene, agr group, ica gene, and IS257) were modeled for the outcome of the EBS assay. The effect of duration of growth was measured 
only for 1 subtype of strains; the agr 2 strains which were IS257 positive were also cultured for $48 \mathrm{~h}$ in the assay before antimicrobial challenge (data not shown).

The CLSI standard susceptibility breakpoints were used to transform the outcomes of the EBS assay binary into susceptible, when the MBEC concentration was lower than the breakpoint, or not susceptible, when the MBEC concentration was higher than the breakpoint. For the first time, the EBS model enabled us to study all of these factors in 1 in vitro model, thus facilitating a quantification of the measure of effect of these factors on the antimicrobial susceptibility. Besides this, the EBS model would be able to facilitate further study of molecular mechanisms behind these differences and the efficacy of novel therapeutic interventions.

The outcomes of the model showed that the duration of the treatment was the most important factor for the outcome of the antimicrobial challenge. This is consistent with the results from in vivo studies (Sol et al., 1997; Sol et al., 2000; Barkema et al., 2006). These studies have also shown that a correlation between the duration of infection and the efficacy of the treatment, and we were able to mimic this in vitro with the EBS assay (data not shown).

Two genotypic factors showed a significant effect in the model: penicillin susceptibility and the presence of IS25\%, alone and as an interaction factor. Previous studies on the presence of IS257 in penicillin-susceptible Staph. aureus bovine mastitis isolates has shown that these strains are all agr 2 and contain 2 copies of IS257 (Melchior et al., 2009) and are represented by the sequenced bovine mastitis isolate Staph. aureus RF122 [National Center for Biotechnology Information (NCBI) reference sequence: NC_007622.1]. In our collection of Staph. aureus bovine mastitis F strains, this type of strain is well represented by a prevalence of $40 \%$ of the isolates, which was later confirmed in the study by van den Borne who found this strain in $33 \%$ of the dairy farms (van den Borne et al., 2010a).

Several publications show that, in general, better mastitis therapy results are achieved with penicillinsusceptible Staph. aureus isolates, although the strains are challenged with another adequate antimicrobial (Ziv and Storper, 1985; Sol et al., 2000; Taponen et al., 2003b). This could not, however, be supported in all investigations (Sol et al., 1997). Based on the results from our in vitro model, we would like to suggest that the results of these in vivo studies could have been influenced by differences in genotypic profile of the strains in the different studies, as some evidence shows that differences exist, with respect to the prevalence of different genotypes, between countries (Smith et al., 2005; Rabello et al., 2007; Hasman et al., 2010). According to our results, only the penicillin-susceptible agr 2 strains with 2 copies of $I S 25 \%$ are significantly more susceptible than other Staph. aureus strains. Based on the multilocus sequence test (MLST) results from (van den Borne et al., 2010a) with another collection of Staph. aureus bovine mastitis isolates from the Netherlands, we assume that these are all CC151 strains. Results from the van den Borne et al. (2010a) study showed that all CC151 strains contained the 2 IS257 copies between the same gene sequences as our agr 2 IS257 strains. Evidence exists that the CC151 is rather prevalent among European bovine mastitis isolates; however, frequencies seem to differ significantly between countries and continents (Smith et al., 2005; Rabello et al., 2007; Hasman et al., 2010).

Although our results might indicate that the CC151 strains are the most susceptible strains, this was not observed in the study by van den Borne et al. (2010a) and we would like to point out one important difference between our assay and that of van de Borne et al. (2010a) with respect to the materials and methods of both studies, which could have influenced the outcomes. The van de Borne et al. (2010a) study includes the cows in their study based on the individual SCC and quarter milk samples are taken after the first elevated SCC ( $\geq 250,000$ cells/mL for multiparous cows and $\geq 150,000$ cells $/ \mathrm{mL}$ for primiparous cows) after 2 consecutive SCC measurements below the parityspecific thresholds. Both the data from their study and our data (not shown) show that IMI with (bovine) penicillin-resistant strains result in higher SCC than IMI infections with penicillin-susceptible strains. Given the fact that the bovine mastitis penicillin-susceptible strains are agr 2, and the penicillin-resistant strains are agr 1, these results are also in line with the outcomes from the experimental mouse infection model by Buzzola et al. (2007). In this mouse model, infections with agr 1 strains from bovine Staph. aureus mastitis resulted in increased internalization, persisted in higher numbers, and resulted in more immune response compared with agr 2 strains. Especially our sample collection, which entered cows in the study based on a lower SCC threshold ( $\geq 120,000$; Melchior et al., 2009) showed that the proposed CC151 strains (penicillin susceptible and IS257 positive) can be found in association with cows with relatively low SCC (data not shown). In general, all chronic Staph. aureus infections lead during the progress of the infection to rising SCC counts, although strain differences with respect to height and increment were found (Haveri et al., 2007). This could indicate that cows infected with CC151 strains are entered in the study after a longer duration of infection compared with cows infected with penicillin-resistant strains. This relatively longer duration of infection for penicillin-susceptible strains could result in a relatively 
lower cure in the clinical study of van den Borne et al. (2010b). Based on the daily experience in practice, the results of several studies (Owens et al., 1997; Deluyker et al., 2005; Barkema et al., 2006; van den Borne et al., 2010a,b), and the results of biofilm antimicrobial susceptibility studies (Amorena et al., 1999; Tré-Hardy et al., 2009; Høiby et al., 2010), it is known that infections of longer duration are in general more difficult to cure with an antimicrobial therapy. Comparing the results from our 24 and $48 \mathrm{~h}$ EBS assays with the agr 2, IS257 strains, which are most likely from CC151, also confirmed a decrease in antimicrobial susceptibility compared with $24 \mathrm{~h}$ biofilms (data not shown).

It might be tempting to conclude, based on our results, that a Staph. aureus infection should simply be treated long enough to obtain therapy success, and this would subsequently lead to the unrestrained use of antimicrobials for bovine mastitis. However, based on previous work, it is known that only infections of relatively short duration are likely to be cured (Pyörälä and Pyörälä, 1998; van den Borne et al., 2010b). The EBS biofilm model is able to confirm this in vitro with bacterial biofilms grown for $48 \mathrm{~h}$ before antimicrobial challenge, and these are less susceptible for antimicrobials also (data not shown; Monzón et al., 2001; Tré-Hardy et al., 2009). Therefore, we would only like to advocate an antimicrobial treatment with an adequate duration for recent Staph. aureus infections. No evidence exists that the repeated use of extended antimicrobial treatments of apparently therapy-resistant infections would be efficacious, because these bacteria have already adapted their lifestyle to antimicrobial treatments (Costerton et al., 1999; Donlan and Costerton, 2002; Melchior et al., 2006b). The mechanisms behind the adaptations in the biofilms that facilitate the survival of antimicrobial therapies seem to be general metabolic mechanisms that are also efficacious against other antimicrobials. Thus far, no therapies seem to be available to overcome this (Mah and O'Toole, 2001). The effect of these adaptations, which are caused by environmental stress signals (i.e., a previous antimicrobial therapy), on the efficacy of antimicrobial therapies could be studied in the EBS model and it would be interesting to learn about the outcomes, and the molecular processes behind this.

The use of the breakpoints of the antimicrobials as a fixed position for the model, even though the breakpoint for neomycin is not established for bovine mastitis, resulted in data that could not be added to the model. Therefore, we would like to point out the raw data from Table 5, as they reveal some interesting points. The antimicrobial concentrations in Table 5 are based on the penicillin concentrations, both for penicillin alone and for the combination with neomycin. This leads us to see that for the penicillin-resistant strains among agr type 1, 3, and 4, a clear added value exists for neomycin in the combination with penicillin with respect to the efficacy of the antimicrobials. However, a considerable number of the agr 2 strains are eradicated at higher penicillin concentrations at $\mathrm{d} 1$ and 3 with the penicillin/neomycin combination compared with penicillin alone. These outcomes agree with a study from Taponen et al. (2003a) in which the efficacy of penicillin was investigated and compared with the efficacy of penicillin with neomycin for penicillin-susceptible gram-positive bacteria. The conclusion from this study was that the traditional use of the penicillin-aminoglycoside combinations in mastitis should be discontinued; however, our results support the use of this combination for penicillin-resistant isolates. The differences found in the agr 2 group strains with respect to the efficacy of the penicillin/neomycin combinations compared with penicillin alone suggest strain differences in response to this antimicrobial combination in Staph. aureus isolates. Our results also raise some questions to the classical idea of a concentration-dependent effect for aminoglycosides, and a time-dependent effect for $\beta$-lactam drugs (Giguère et al., 2006). The EBS biofilm model, containing bacteria in another range of metabolic states compared with the CLSI model, shows that aminoglycosides are also more efficacious when applied for longer durations, and that $\beta$-lactam drugs are also more efficacious at higher concentrations.

The outcomes of this model show significant differences regarding the antimicrobial susceptibility in a biofilm for different subtypes of Staph. aureus, regardless of similarities in classical antimicrobial susceptibility according to CLSI guidelines. The results of multicountry experiments and clinical trials, which are sometimes performed for registration of veterinary products, executed in countries with differences in prevalence of strain subtypes, might be able to influence the outcomes. A recent example of these effects might be the results of the efficacy of 3 cephalosporin-based antimicrobials for mastitis in the United Kingdom, France, and Germany (Bradley and Green, 2009). Here, significant differences were found for the outcomes between the contributing countries. Unfortunately, however, the factors used in the models reveal little of the subtypes of Staph. aureus strains present in the 3 countries in the study; only the significant effect of individual SCC before treatment hints at the influence of strain type on the efficacy of the treatment. The EBS model would be able to model the strain differences without the background noise of in vivo differences, and facilitate a clear comparison of the used antimicrobials. Obviously, the model is not able to account for the differences in kinetic profiles of 
these antimicrobials, or the effect of infection dynamics and we would need good comparative in vivo data to establish treatment efficacy.

\section{CONCLUSIONS}

In this study, we used the EBS assay to model the measure the effect of several treatment variables on the efficacy of antimicrobials on biofilm-growing Staph. aureus bovine mastitis isolates. The outcomes reveal that the duration of antimicrobial treatment and the type of strain are important factors for the outcomes of the treatment. The EBS assay facilitates the simultaneous measurement of different treatment and strain factors under the same conditions, thus opening the opportunity to compare effect of these factors in a logistic regression model. Besides this, the EBS assay would also be able to facilitate further studies regarding the molecular mechanisms of the different strain types, which are related to the differences in antimicrobial susceptibility. Furthermore, the assay could also facilitate the study of novel therapies for bacterial biofilms.

\section{ACKNOWLEDGMENTS}

This project was part of the 5-yr mastitis program of the Dutch Udder Health Centre (Deventer, the Netherlands) and was financially supported by the Dutch Dairy Board (Zoetermeer, the Netherlands). We greatly appreciate the suggestions and comments from the anonymous reviewers of the manuscript.

\section{REFERENCES}

Amorena, B., E. Gracia, M. Monzón, J. Leiva, C. Oteiza, M. Pérez, J.L. Alabart, and J. Hernández-Yago. 1999. Antibiotic susceptibility assay for Staphylococcus aureus in biofilms developed in vitro. J. Antimicrob. Chemother. 44:43-55.

Barkema, H. W., Y. H. Schukken, and R. N. Zadoks. 2006. Invited review: The role of cow, pathogen, and treatment regimen in the therapeutic success of bovine Staphylococcus aureus mastitis. J. Dairy Sci. 89:1877-1895.

Bates, D., M. Maechler, and B. Dai. 2008. lme4: Linear mixed-effects models using S4 classes. $\mathrm{R}$ package version 0.999375-28. Accessed March 2010. http://lme4.r-forge.r-project.org.

Bradley, A. J., and M. J. Green. 2009. Factors affecting cure when treating bovine clinical mastitis with cephalosporin-based intramammary preparations. J. Dairy Sci. 92:1941-1953.

Buzzola, F. R., L. P. Alvarez, L. P. N. Tuchscherr, M. S. Barbagelata, S. M. Lattar, L. Calvinho, and D. O. Sordelli. 2007. Differential abilities of capsulated and noncapsulated Staphylococcus aureus isolates from diverse agr groups to invade mammary epithelial cells. Infect. Immun. 75:886-891.

Ceri, H., M. E. Olson, C. Stremick, R. R. Read, D. Morck, and A. Buret. 1999. The Calgary Biofilm Device: New technology for rapid determination of antibiotic susceptibilities of bacterial biofilms. J. Clin. Microbiol. 37:1771-1776.

Chan, W. C., B. J. Coyle, and P. Williams. 2004. Virulence regulation and quorum sensing in staphylococcal infections: Competitive AgrC antagonists as quorum sensing inhibitors. J. Med. Chem. 47:4633-4641.
Costerton, J. W., P. S. Stewart, and E. P. Greenberg. 1999. Bacterial biofilms: A common cause of persistent infections. Science 284:1318-1322.

Cramton, S. E., C. Gerke, N. F. Schnell, W. W. Nichols, and F. Götz. 1999. The intercellular adhesion (ica) locus is present in Staphylococcus aureus and is required for biofilm formation. Infect. Immun. 67:5427-5433.

Deluyker, H. A., S. T. Chester, and S. N. Van Oye. 1999. A multilocation clinical trial in lactating dairy cows affected with clinical mastitis to compare the efficacy of treatment with intramammary infusions of a lincomycin/neomycin combination with an ampicillin/cloxacillin combination. J. Vet. Pharmacol. Ther. 22:274-282.

Deluyker, H. A., S. N. Van Oye, and J. F. Boucher. 2005. Factors affecting cure and somatic cell count after pirlimycin treatment of subclinical mastitis in lactating cows. J. Dairy Sci. 88:604-614.

Donlan, R. M., and J. W. Costerton. 2002. Biofilms: Survival mechanisms of clinically relevant microorganisms. Clin. Microbiol. Rev. 15:167-193.

Fox, L. K., R. N. Zadoks, and C. T. Gaskins. 2005. Biofilm production by Staphylococcus aureus associated with intramammary infection. Vet. Microbiol. 107:295-299.

Giguère, S., J. F. Prescott, J. D. Baggot, R. D. Walker, and P. M. Dowling. 2006. Antimicrobial therapy in Veterinary Medicine. 4th ed. Blackwell Publishing, Oxford, UK.

Gilot, P., G. Lina, T. Cochard, and B. Poutrel. 2002. Analysis of the genetic variability of genes encoding the RNA III-activating components Agr and TRAP in a population of Staphylococcus aureus strains isolated from cows with mastitis. J. Clin. Microbiol. 40:4060-4067.

Hasman, H., A. Moodley, L. Guardabassi, M. Stegger, R. L. Skov, and F. M. Aarestrup. 2010. spa type distribution in Staphylococcus aureus originating from pigs, cattle and poultry. Vet. Microbiol. 141:326-331.

Haveri, M., A. Roslöf, L. Rantala, and S. Pyörälä. 2007. Virulence genes of bovine Staphylococcus aureus from persistent and nonpersistent intramammary infections with different clinical characteristics. J. Appl. Microbiol. 103:993-1000.

Haveri, M., S. Taponen, J. Vuopio-Varkila, S. Salmenlinna, and S. Pyörälä. 2005. Bacterial genotype affects the manifestation and persistence of bovine Staphylococcus aureus intramammary infection. J. Clin. Microbiol. 43:959-961.

Høiby, N., T. Bjarnsholt, M. Givskov, S. Molin, and O. Ciofu. 2010. Antibiotic resistance of bacterial biofilms. Int. J. Antimicrob. Agents 35:322-332.

Jarraud, S., C. Mougel, J. Thioulouse, G. Lina, H. Meugnier, F. Forey, X. Nesme, J. Etienne, and F. Vandenesch. 2002. Relationships between Staphylococcus aureus genetic background, virulence factors, agr groups (alleles), and human disease. Infect. Immun. 70:631-641.

Ji, G., R. Beavis, and R. P. Novick. 1997. Bacterial interference caused by autoinducing peptide variants. Science 276:2027-2030.

Lyon, G. J., J. S. Wright, T. W. Muir, and R. P. Novick. 2002. Key determinants of receptor activation in the agr autoinducing peptides of Staphylococcus aureus. Biochemistry 41:10095-10104.

Mah, T.-F. C., and G. A. O'Toole. 2001. Mechanisms of biofilm resistance to antimicrobial agents. Trends Microbiol. 9:34-39.

MARAN. 2003-2007. MARAN: Monitoring of Antimicrobial Resistance and Antibiotic usage in Animals in the Netherlands in 2003 , 2004, 2005, and 2006/2007. CVI-Lelystad, the Netherlands. www. cvi.wur.nl.

MARAN. 2005. MARAN-2005: Monitoring of Antimicrobial Resistance and Antibiotic Usage in Animals in the Netherlands in 2005. CIDC-Lelystad, the Netherlands. www.cidc-lelystad.nl.

Melchior, M. B. 2007. Biofilms: Implications for the therapy of bovine Staphylococcus aureus mastitis. $\mathrm{PhD}$ Thesis. University of Utrecht, Utrecht, the Netherlands.

Melchior, M. B., J. Fink-Gremmels, and W. Gaastra. 2006a. Comparative assessment of the antimicrobial susceptibility of Staphylococcus aureus isolates from bovine mastitis in biofilm versus planktonic culture. J. Vet. Med. B Infect. Dis. Vet. Public Health $53: 326-332$. 
Melchior, M. B., J. Fink-Gremmels, and W. Gaastra. 2007. Extended antimicrobial susceptibility assay for Staphylococcus aureus isolates from bovine mastitis growing in biofilms. Vet. Microbiol. 125:141-149.

Melchior, M. B., H. Vaarkamp, and J. Fink-Gremmels. 2006b. Biofilms: A role in recurrent mastitis infections? Vet. J. 171:398-407.

Melchior, M. B., M. H. van Osch, R. M. Graat, E. van Duijkeren, D. J. Mevius, M. Nielen, W. Gaastra, and J. Fink-Gremmels. 2009. Biofilm formation and genotyping of Staphylococcus aureus bovine mastitis isolates: Evidence for lack of penicillin-resistance in Agrtype II strains. Vet. Microbiol. 137:83-89.

Monzón, M., C. Oteiza, J. Leiva, and B. Amorena. 2001. Synergy of different antibiotic combinations in biofilms of Staphylococcus epidermidis. J. Antimicrob. Chemother. 48:793-801.

O'Gara, J. P. 2007. ica and beyond: Biofilm mechanisms and regulation in Staphylococcus epidermidis and Staphylococcus aureus. FEMS Microbiol. Lett. 270:179-188.

Oliver, S. P., B. E. Gillespie, S. J. Headrick, H. Moorehead, P. Lunn, H. H. Dowlen, D. L. Johnson, K. C. Lamar, S. T. Chester, and W. M. Moseley. 2004. Efficacy of extended ceftiofur intramammary therapy for treatment of subclinical mastitis in lactating dairy cows. J. Dairy Sci. 87:2393-2400.

Olsen, J. E., H. Christensen, and F. M. Aarestrup. 2006. Diversity and evolution of blaZ from Staphylococcus aureus and coagulasenegative staphylococci. J. Antimicrob. Chemother. 57:450-460.

Olson, M. E., H. Ceri, D. W. Morck, A. G. Buret, and R. R. Read. 2002. Biofilm bacteria: Formation and comparative susceptibility to antibiotics. Can. J. Vet. Res. 66:86-92.

Owens, W. E., C. H. Ray, J. L. Watts, and R. J. Yancey. 1997. Comparison of success of antibiotic therapy during lactation and results of antimicrobial susceptibility tests for bovine mastitis. J. Dairy Sci. 80:313-317.

Pyörälä, S. H. K., and E. O. Pyörälä. 1998. Efficacy of parenteral administration of three antimicrobial agents in treatment of clinical mastitis in lactating cows: 487 cases (1989-1995). J. Am. Vet. Med. Assoc. 212:407-412.

Rabello, R. F., B. M. Moreira, R. M. M. Lopes, L. M. Teixeira, L. W. Riley, and A. C. Castro. 2007. Multilocus sequence typing of Staphylococcus aureus isolates recovered from cows with mastitis in Brazilian dairy herds. J. Med. Microbiol. 56:1505-1511.

Sidhu, M. S., E. Heir, T. Leegaard, K. Wiger, and A. Holck. 2002. Frequency of disinfectant resistance genes and genetic linkage with $\beta$-lactamase transposon Tn552 among clinical staphylococci. Antimicrob. Agents Chemother. 46:2797-2803.

Smith, E. M., L. E. Green, G. F. Medley, H. E. Bird, L. K. Fox, Y. H. Schukken, J. V. Kruze, A. J. Bradley, R. N. Zadoks, and C. G. Dowson. 2005. Multilocus sequence typing of intercontinental bovine Staphylococcus aureus isolates. J. Clin. Microbiol. 43:47374743.

Sol, J., O. C. Sampimon, H. W. Barkema, and Y. H. Schukken. 2000. Factors associated with cure after therapy of clinical mastitis caused by Staphylococcus aureus. J. Dairy Sci. 83:278-284.
Sol, J., O. C. Sampimon, J. J. Snoep, and Y. H. Schukken. 1997. Factors associated with bacteriological cure during lactation after therapy for subclinical mastitis caused by Staphylococcus aureus. J. Dairy Sci. 80:2803-2808.

Stewart, P. S. 2002. Mechanisms of antibiotic resistance in bacterial biofilms. Int. J. Med. Microbiol. 292:107-113.

Taponen, S., K. Dredge, B. Henriksson, A.-M. Pyyhtiä, L. Suojala, R. Junni, K. Heinonen, and S. Pyörälä. 2003a. Efficacy of intramammary treatment with procaine penicillin $G$ vs. procaine penicillin $\mathrm{G}$ plus neomycin in bovine clinical mastitis caused by penicillinsusceptible, gram-positive bacteria-A double blind field study. J. Vet. Pharmacol. Ther. 26:193-198.

Taponen, S., A. Jantunen, E. Pyörälä, and S. Pyörälä. 2003b. Efficacy of targeted 5-day combined parenteral and intramammary treatment of clinical mastitis caused by penicillin-susceptible or penicillin-resistant Staphylococcus aureus. Acta Vet. Scand. 44:53-62.

R Development Core Team. 2008. R: A language and environment for statistical computing. Accessed March 2010. http://www. R-project.org. R. Foundations for Statistical Computing, Vienna, Austria.

Tré-Hardy, M., H. Traore, N. El Manssouri, F. Vanderbist, M. Vaneechoutte, and M. J. Devleeschouwer. 2009. Evaluation of long-term co-administration of tobramycin and clarithromycin in a mature biofilm model of cystic fibrosis clinical isolates of Pseudomonas aeruginosa. Int. J. Antimicrob. Agents 34:370-374.

van den Borne, B. H. P., M. Nielen, G. van Schaik, M. B. Melchior, T. J. G. M. Lam, and R. N. Zadoks. 2010a. Host adaptation of bovine Staphylococcus aureus seems associated with bacteriological cure after lactational antimicrobial treatment. J. Dairy Sci. 93:2550-2558.

van den Borne, B. H. P., G. van Schaik, T. J. G. M. Lam, and M. Nielen. 2010b. Therapeutic effects of antimicrobial treatment during lactation of recently acquired bovine subclinical mastitis: Two linked randomized field trials. J. Dairy Sci. 93:218-233.

Vasudevan, P., M. K. Nair, T. Annamalai, and K. S. Venkitanarayanan. 2003. Phenotypic and genotypic characterization of bovine mastitis isolates of Staphylococcus aureus for biofilm formation. Vet. Microbiol. 92:179-185.

Ziebuhr, W., V. Krimmer, S. Rachid, I. Lössner, F. Götz, and J. Hacker. 1999. A novel mechanism of phase variation of virulence in Staphylococcus epidermidis: Evidence for control of the polysaccharide intercellular adhesin synthesis by alternating insertion and excision of the insertion sequence element IS256. Mol. Microbiol. $32: 345-356$.

Ziv, G., and M. Storper. 1985. Intramuscular treatment of subclinical staphylococcal mastitis in lactating cows with penicillin G, methicillin and their esters. J. Vet. Pharmacol. Ther. 8:276-283. 